\title{
Traditional Kitchen Design for Sustainable Low-Income Dwellings in Developing Countries
}

\author{
Eugene E. Atamewan ${ }^{1} \&$ Ekpo E Otu ${ }^{2}$ \\ ${ }^{1}$ Department of Architecture, Faculty of Environmental Sciences, Cross River University of Technology, \\ Calabar, Nigeria \\ Correspondence: Eugene E. Atamewan, Department of Architecture, Faculty of Environmental Sciences, Cross \\ River University of Technology, PMB 1123, Calabar, Cross River State, Nigeria. E-mail: \\ atamewaneugene@gmail.com
}

Received: October 8, 2018 Accepted: November 28, 2018 Online Published: November 29, 2018

doi:10.5539/jsd.v11n6p59 URL: https://doi.org/10.5539/jsd.v11n6p59

\begin{abstract}
The place of kitchens in contemporary designs is quite different from the traditional designs in terms of location, aesthetics and furnishing. Thus, this paper discussed development in kitchen designs over the past centuries and place emphasis on sustainable low-income kitchen design. The study examined the location of kitchens in contemporary dwellings in comparison with traditional dwellings in order to create a hybrid kitchen design that is sustainable, attainable and acceptable to contemporary and traditional individuals. Research methodology involved descriptive survey; with primary data obtained using structured questionnaire, systematic observation and interview with occupants of buildings in Awi community, Akamkpa Local Government Area of Cross River State, Nigeria which is the study area. These were complemented with photographs of kitchens in the existing buildings within the area of study. 50 buildings purposely selected were studied to determine the designs, and placement/location of kitchens in these buildings in relation to the contemporary buildings respectively. Finally, the data collected were analyzed using simple statistical tool to obtain percentages, rankings and relative significance index (RSI) respectively to determine the reasons for the design and location of the kitchen. The result shows that of the five variables examined, cultural influence was the most significant reason for the location of kitchens outside the housing unit. The recommendation is that low-income dwelling should have kitchen space within in addition to the attached or detached kitchens in their dwellings.
\end{abstract}

Keywords: kitchen, culture, dwellings, sustainable design

\section{Introduction}

Architectural piece is characterized by functional spaces in order to give the the end users the desired comfort. Thus, amongst the component spaces in any residential building, the kitchen stands out as one of the most important functional part. Kitchen can be described as that part of the building designed and equipped for preparation of all forms of meals needed by the occupants of the building (Cromley, 2011). Kitchens are either located within the interior of the building or outside usually attached/detached depending on the type of building. However, in recent times, the function of kitchens has not been limited to meal preparation but also dining, laundry, storage of food items as well as entertainment. Hence, modern kitchens are designed to accommodate facilities like kitchen cabinet, cooking units, sinks for dishwashing and refrigerators. (Borson, 2011).

Over the past decades, housing architecture has experienced changes in various dimensions and these changes are as a result of changes in human taste, status and lifestyles of individuals. Also, the changes have been practically notable in all parts of the residential buildings including the kitchen. This is the reason kitchens today have become the central of attraction and it is giving architects tough time in conceiving the ideas of producing satisfactory kitchen designs but this was not the case before the twentieth century (Bech-Danielsen, 2012).

The kitchen has become one of the most important parts of the house because of it specific purpose. It is regarded as the heart of the home and one area of the house where there is family activity. Every occasion or celebration ha a link with the kitchen one way or another. It is also the most expensive activity space in the house if one considers and sum up all the expenses associated with cabinetry, counter tops, appliances, and lighting (Borson, 2011). 
Sustainable housing development is viewed by built environment professionals and environmental specialists as a way through which nature-given resources are protected and preserved while also promoting the maximum utilization of freely available and replaceable sources of energy during housing construction. An important feature of sustainable housing concept is the integration of natural day lighting and ventilation features into the building design. In other words, natural light and air are allowed to flow freely and unhindered into the building interiors. Sustainable housing concept encourages building materials reuse or recycle to reduce negative environmental impact, and cost less in the long run Thus, the concept of sustainable housing development encourages and support low-income designs and construction techniques (Atamewan, 2017).

\section{Brief History of Kitchen}

Historically, until the $18^{\text {th }}$ century, food was cooked over an open fire and water was usually brought from outdoor sources such as wells, pumps or springs until the $19^{\text {th }}$ century. So it was the invention of cooking stove and the development of water infrastructure that could supply water to homes that led to the evolution and changes in the architecture of the kitchen. In the early part of the $20^{\text {th }}$ century, paying attention to kitchen design was never an issue because the kitchen was exclusively meant for servants and cooks. Cooking in the kitchen was regarded as hard and dirty works hence women of the high and middle class then had nothing to do in or with the kitchen (Sudjic, 1999; Burnett, 1978).

In the ancient Greece, open patio served as kitchens which were assessed from a central courtyard for women. Only the wealthy ones had separate room as kitchen close to their bathrooms (so that both rooms could be heated by the kitchen fire).in the Roman empire, only the roman villa had its kitchen incorporated into the building s a separate room set apart for reasons of smoke and status reason of kitchen being used by slaves.

During the middle age, the kitchen was still not a major component of the building hence it was not affected by any advancement in architecture. The kitchen was located between the entrance and the fireplace. Most of the buildings had a small hole in their roof which served as a chimney through which smokes escaped. Open fire was still the method of cooking food which also served the purpose of heating and lighting the rooms. The European Medieval kitchens were dark smoky and sooty places which gave them the name "smoke kitchen" (Snodgrass, 2004).

In Colonial America era, kitchen had to be built as separate rooms located behind the living and dining rooms. This was also to double as houses for servants for social status sake. There was also the summer kitchen built to prepare food for harvest workers during the summer season. The advancement in technological innovation brought in the iron stove and changed kitchen perception completely. The introduction of the Franklin stove in 1740 and Rumford stove in 1800 was a major breakthrough in industrialization which altered architectural history in terms of kitchen designs.

Consequently, the industrial revolution in the late $19^{\text {th }}$ and early $20^{\text {th }}$ centuries introduced the use of potable water and gas within the home and the invention of electricity altered the history and design of kitchen and cooking. Emphasis in kitchen design and arrangement shifted to interior aesthetics with the introduction of wall and floor tiles, kitchen cabinets, work bench as well as dining space (Bech-Danielsen, 2012; Cromley, 2011).

\section{Universal Design Concept}

There is the concept of universal design which is a developing design philosophy which is defined as the design of spaces, products and environments that is meant for and utilizable by all categories of people, to the greatest degree possible, without the need for adaptation or specialized design (Canada Mortgage and Housing Corporation [CMHC], 2010).

However, some design elements associated with a universal kitchen design include the following:

a. The location of the kitchen in the dwelling

b. The location of appliances and workspaces in the kitchen

c. The floor, wall and counter surfaces

d. Ways to reduce noise

e. The type of lighting in the kitchen

f. The overall use of colour and space.

\subsection{Principles of Universal Design}

According to CMHC (2010), there are about seven basic principles of universal design that makes a kitchen efficient. These are: 


\section{1) Equitability of use}

This principle states that the design should provide an equal level of safety to all users and also appealing to all. This means that the kitchen design must provide equitable access for everyone in a proper manner.

2) Flexibility in use

The principle of flexibility entails that house or kitchen design should be able to accommodate a broad range of user preference and abilities and suit individuals taste as well as adapt to everyday changes.

3) Simplicity

This principle implies that the design of the home, kitchen and devices be made simple and work intuitively, that is, the design should be easily understood by all persons irrespective of user's experience.

4) Perceptible information

This principle emphasizes that enough information is provided in different modes for all categories of users to fully use the elements of the home for safety through the engagement of their sense organs as they interact with the home environment.

\section{5) Tolerance for error}

This principle implies design considerations that include fail-safe features while providing guidelines on the use of the space for safety. There is room for tolerance for error though at a minimal level.

6) Size and Space for use

This principle suggests that adequate sizes of spaces for access, circulation, work, and equipment control be provided for optimal benefit and safety of all family members and visitors.

7) Low physical effort

This principle spells out the limitation to be experienced with the strength, resilience and dexterity necessary to access or use spaces, control and utilize products.

\section{Kitchen Design}

As seen in recent times, kitchen designs have assumed remarkable changes. The desire of everyone is to have a kitchen that is safe, comfortable and spacious. The taste and variety in the needs of different categories of people who visits our homes, lives and uses the kitchen calls for a design and construction of spaces in dwellings that will accommodate a larger number of these people Thus, for enlarged usability of all groups of people, the universal design concept of "aging in place", flexibility and adaptability are incorporated into kitchen designs (Kinchin \& Aidan, 2011; Overy, 2008).

\subsection{Kitchen Design Requirements}

It should be noted that the foundation of a good kitchen design is the design that is efficient through the maximization of independence and convenience to users. There are certain design requirements that will make a kitchen effective, functional and usable by all categories of people in the dwellings. These requirements are (i) Efficient design; (ii)Adaptability; (iii)Audibility (iv)Space maneuvering (v)Minimal effort(vi)Ease of cleaning and (vii)Safety (Kinchin \& Aidan, 2011).

Importantly, a good design usually begins with planning which is also the foundation for an efficient kitchen. Designing and planning of an efficient kitchen involves keeping the work triangle compact. The work triangle formed by the sink, stove (cooking unit) and refrigerator have remained the conventional method of designing kitchen but very recently, kitchen designers have realized the need to expand the work triangle to accommodate more work areas, garbage disposal and dishwasher so as to prevent limitation in circulation in and around the kitchen.( CMHC 2010;Lupton,.\& Miller,1996).

Kitchen design is determined by the orderly and regular movements of family members and visitors who use the kitchen and this forms the basis of a kitchen design with a work triangle that meets users' needs. Nevertheless, the low-income kitchen is not based on most of the above stated requirements and principle, thus the work triangle becomes a mirage and insignificant in traditional low-income kitchen design.

\subsection{Types of Kitchen}

The types of kitchen available are usually determined by the arrangements of the kitchen work triangle, thus the following kitchen types exist according to (Gilly, 1997).

(i) Galley-style kitchen: this is generally sub-divided into two namely one-way galley-style kitchen and two-way 
galley-style kitchen respectively. What is important here is that grants users more than single entry and exit points but limits those on wheel chairs creating turning point problems to them

(a) One-way galley-style kitchen: This is also called a single-file kitchen; usually not adequate and is only suitable with constrained space. It has one cabinet along one wall; thereby making the work triangle to collapse to a single line..

(b) Two-way galley-style kitchen: This is also called a double-file kitchen which is the popular conventional work kitchen that has two rows of cabinets at opposite walls, with one containing the cooking unit or stove and the sink, the other the refrigerator.

(ii) U-shaped kitchen: This is a typical work kitchen where the sink is placed at the base of the "U". This type of kitchen has cabinets along three walls and it is the most convenient layout for one or two people working in a kitchen.

(iii) L-shaped kitchen: This type of kitchen has the advantage of accommodating more people to work in the kitchen because it has cabinets in two adjacent walls thereby providing several work surfaces. It may be with or without an island, but the work triangle is preserved,

(iv) The block kitchen: This type of kitchen is also called island. It is well suited for an open kitchen arrangement. Here the cooking unit (stove) or both the stove and the sink are positioned where an L or U kitchen would have a table, in a free-standing "island", separated from the other cabinets. This is to make the stove accessible from all sides such that two persons can cook together, allowing for contact with guests or the rest of the family. Also, the kitchen island's counter-top functions as an overflow-surface for serving and eating buffet style meals or breakfast and snacks.

(v) G-kitchen: This type of kitchen is planned to support two work triangles as well as provide additional work and storage spaces. The G-kitchen like the U-kitchen has cabinets along three walls, but with a partial fourth wall. Also, with a double basin sink at the corner of the G-shape. Today, the G-kitchen is customized to splits the $\mathrm{G}$ into two L-shaped components, which in effect adds a smaller L-shaped island to the L-kitchen.

\section{The Traditional Kitchen: The influence of Culture and Income}

As stated above, today's contemporary kitchen demonstrates and display affluence, personalities and aesthetic appeal which negate the principles of universal and sustainable design. Thus, the majority of the populace both in urban and rural areas are excluded from the design scheme. In the traditional low-income kitchen design, the culture and income level of the people plays a significant role. This explains the size, location, design and furnishing of kitchens. Kitchens in low-income dwellings (Figures $1 \& 2$ ) are either located within the building or outside which are attached or detached usually without furnishing (Atamewan, \& Olagunju, 2017). 


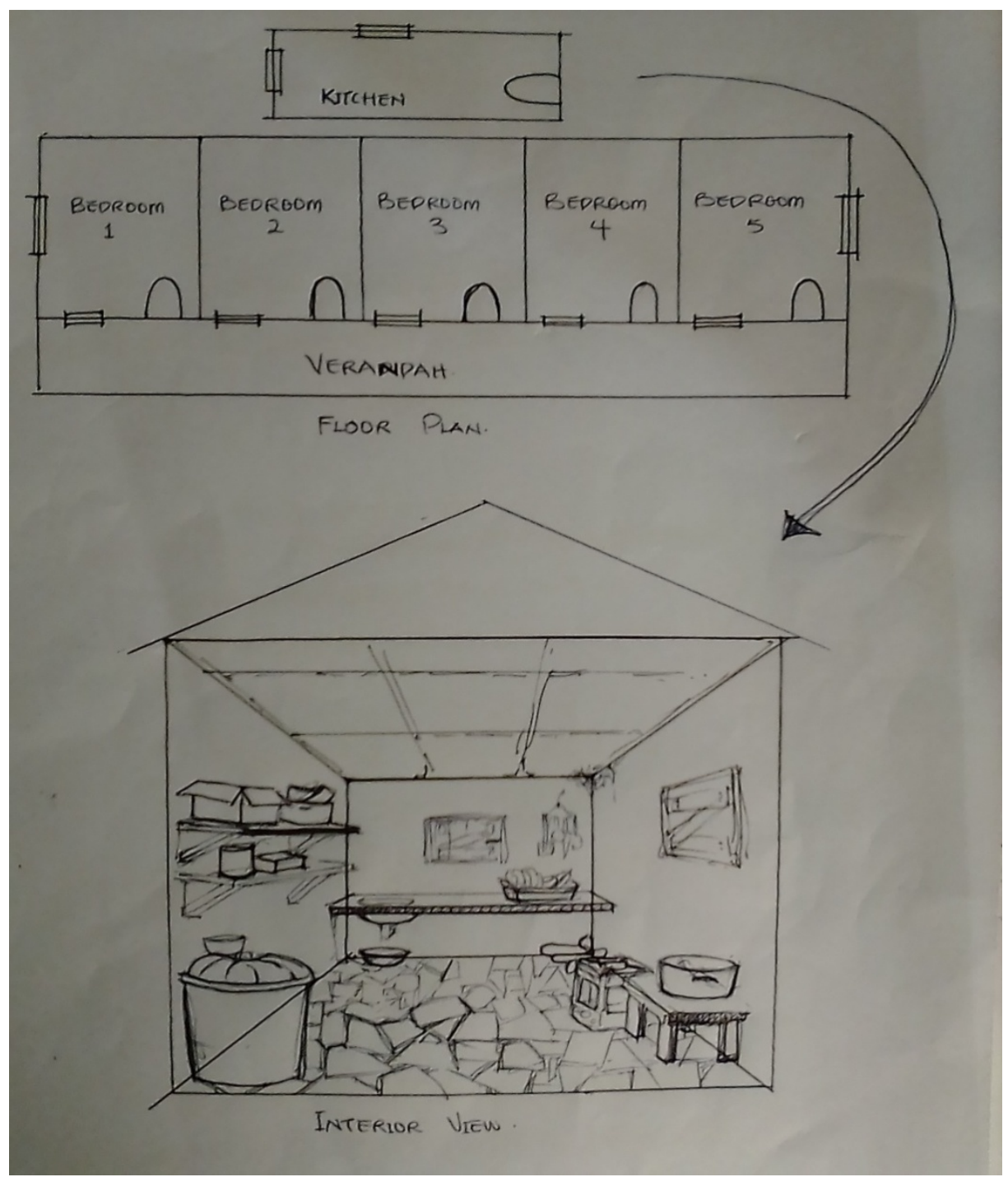

Figure 1. Traditional kitchen attached to main building with interior view

Sources: Author's fieldwork 


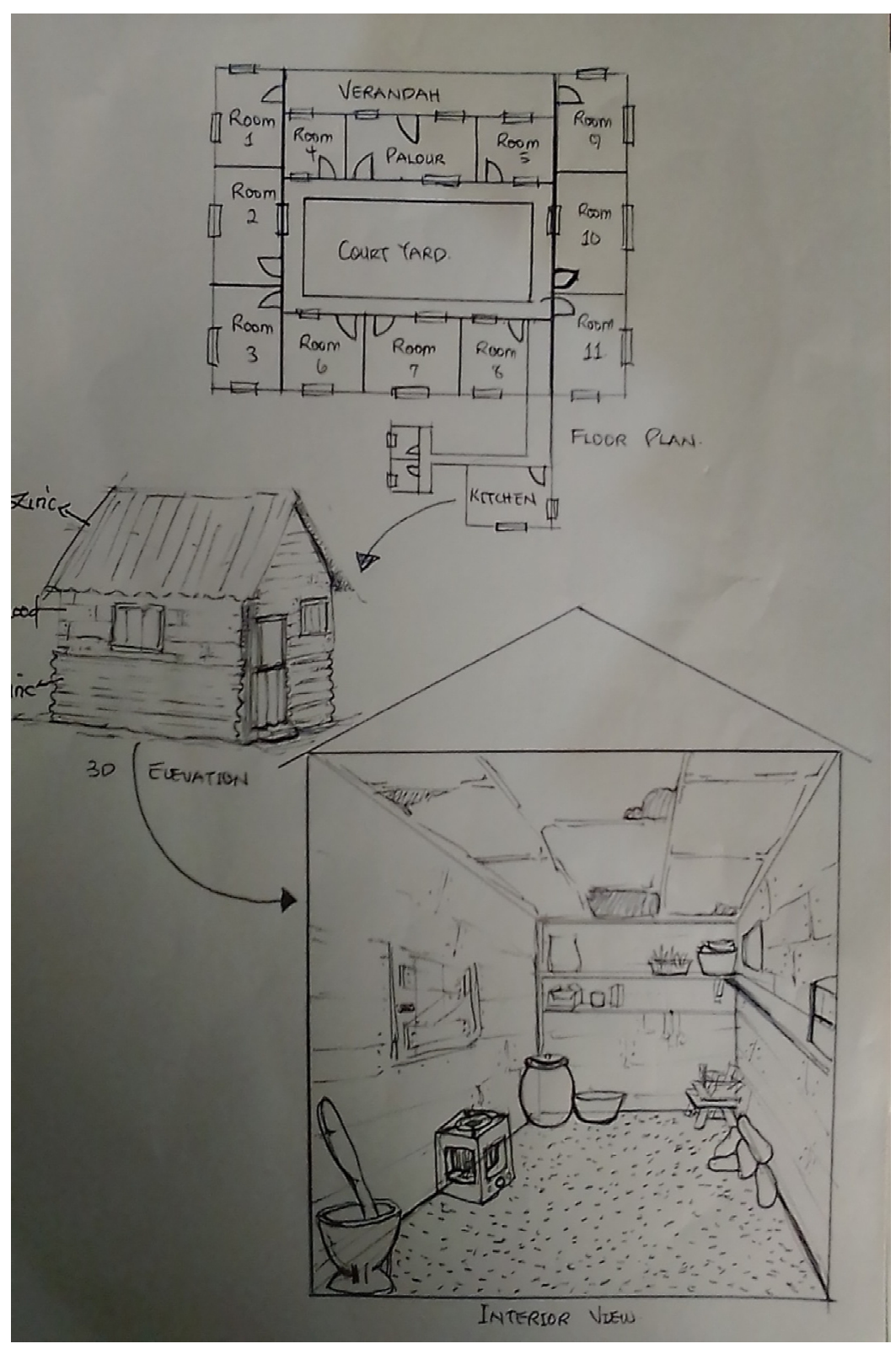

Figure 2.Traditional kitchen detached from main building with interior view Sources: Author's fieldwork 
Architecture has never existed in isolation but rather it is dictated by the cultural traits, beliefs and traditions of the people which in turn shape the forms, design and planning of spaces. The foundation of architecture is established on the culture of any given society thus making architecture the objective image of the societal culture. The lifestyle and socio-cultural characteristics of individuals in a society has great influence on the planning and design of the housing units and by extension the environment. Thus, the arrangement and space formation is a direct influence of culture (Atamewan, 2017; Ettehad, Azeri,\& Kari, 2014).

Also, one major principle of sustainable design is accessibility and affordability by the end users. This is why culture and income plays a vital role in depicting the outcome of the architectural space within the environment. Thus, every people and ethnic group presents specific architecture in harmony with their cultural traits at any given time (Gopinath, \& Kulkarni, 2014; Shayan, 2011; Parvizi, 2009).

\section{Research Methodology}

Research methodology involves descriptive survey, thus, primary data, was obtained using structured questionnaire, systematic observation and interview with occupants of buildings in the study area. These were complemented with sketches of traditional kitchen, photographs of kitchens in the existing buildings within the area of study (Awi, Akamkpa Local Government Area of Cross River State). 50 buildings purposely selected were studied to determine the designs, and placement/ location of kitchens in these buildings in relation to the contemporary buildings occupied by the medium and high income groups respectively. Finally, the data collected were analyzed using simple statistical tool to obtain percentages, rankings and relative significance index (RSI) respectively to determine the reasons for the design and location of the kitchen.

\section{Result, Discussions and Findings}

The calculation of the relative significance index (RSI) shown in Table 1 below on the reasons for the location of kitchen in and around the dwelling units in the study area indicates that from the variables listed, Cultural influence with RSI value of 0.632 ranked first. Income level with $0.548 \mathrm{RSI}$ value is ranked second. This is followed closely by convenience with 0.500 RSI value. The forth ranked variable is Choice/taste which has a RSI value of 0.468 , while the least ranked variable with RSI value of 0.428 is unstated reason. The result signify that among the five variables examined in terms of the reason for the location of kitchen in different area of the dwelling units in the study area, cultural influence is the most significant, thus implying that it contribute most to the overall reason for the location of kitchen in the housing units. This is followed by income level which implies that income at the disposal of the users determine the type and placement of kitchen in their dwellings. The least significant for the location of kitchen is the unstated reasons.

Table 1. Relative significant index of reasons for different location of kitchen in the dwelling units

\begin{tabular}{llllllllll}
\hline REASON & $\mathbf{1}$ & $\mathbf{2}$ & $\mathbf{3}$ & $\mathbf{4}$ & $\mathbf{5}$ & TOTAL & TWV & RSI & RANK \\
\hline Choice/Taste & 14 & 15 & 15 & 2 & 4 & 50 & 117 & 0.468 & 4 \\
Income Level & 3 & 14 & 23 & 7 & 3 & 50 & 137 & 0.548 & 2 \\
Convenience & 11 & 13 & 17 & 8 & 1 & 50 & 125 & 0.500 & 3 \\
Cultural Influence & 4 & 13 & 12 & 13 & 8 & 50 & 158 & 0.632 & 1 \\
Unstated reason & 13 & 24 & 8 & 3 & 2 & 50 & 107 & 0.428 & 5 \\
\hline
\end{tabular}

Source: Authors' fieldwork

\subsection{Location of Kitchen in the Housing Units}

On the location of kitchen, of the fifty houses studied, 5 houses representing $10 \%$ had their kitchen located inside (within) the dwelling unit, 8 representing 16\% had their kitchen outside (attached), 32 houses representing 64\% had their kitchen located outside (detached) while the remaining 5 houses representing $10 \%$ had no kitchen at all, as revealed in Figure 3. The outside locations of the kitchen were either at the back or at the side of the housing units. 


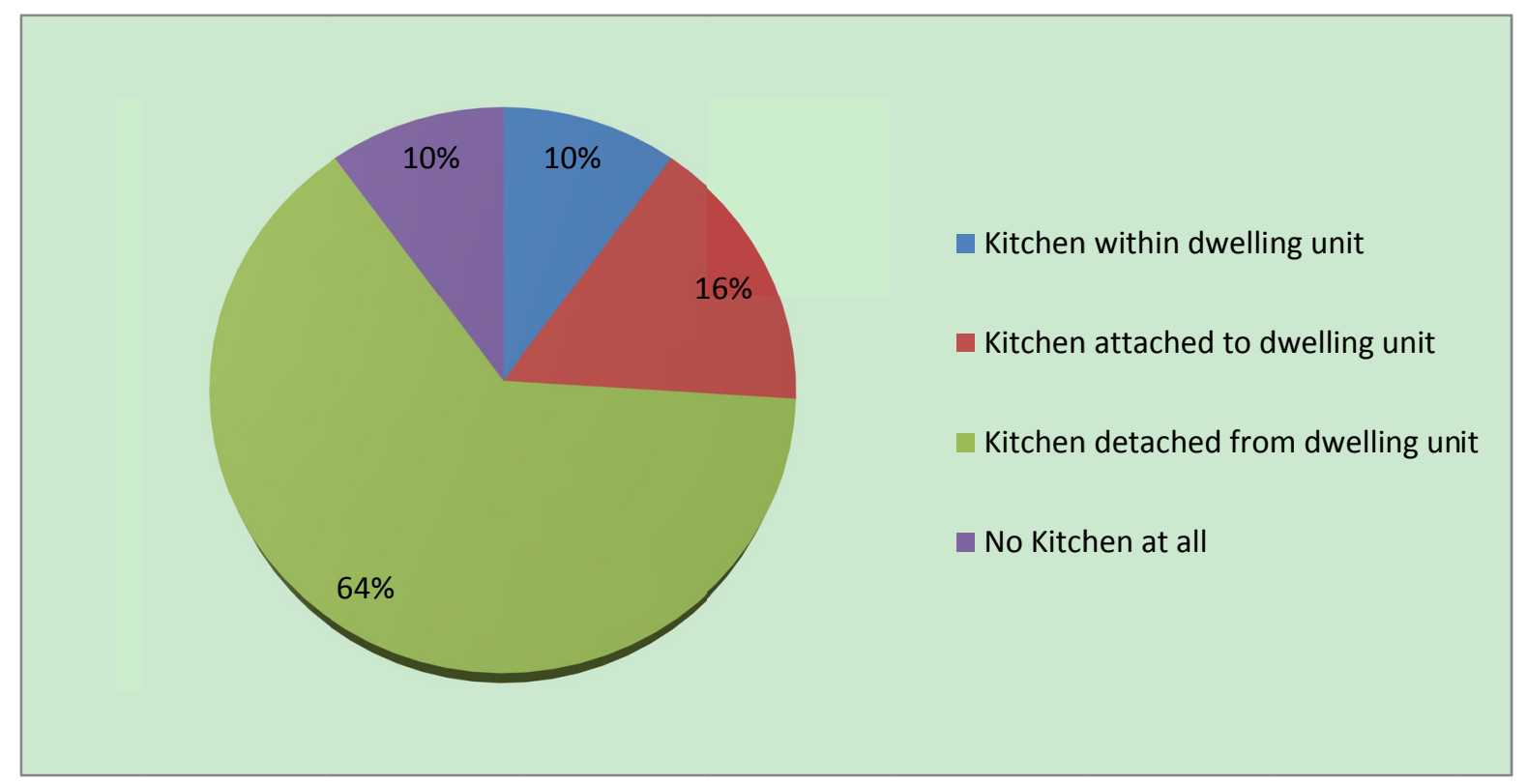

Figure 3. Location of kitchen in the housing units

Source: Authors' fieldwork

Additional investigation show that these kitchens were constructed with temporary materials such as bamboo, woods, zinc sheets which suggests that this service space does not represent major consideration in the design of dwellings across the study area (figure 3). However, what is strange about the study was that occupants of contemporary buildings having well designed kitchens within their building do not make use of the kitchen space. Rather, they chose to use an improvised kitchen space outside to prepare their meals. The reasons advanced for this practice was that they like to cook in a natural kitchen setting with fire wood which was more readily available, adaptable and even more affordable than either kerosene or gas used in the modern kitchens which emphasizes preference for culture and income (Figure 4).

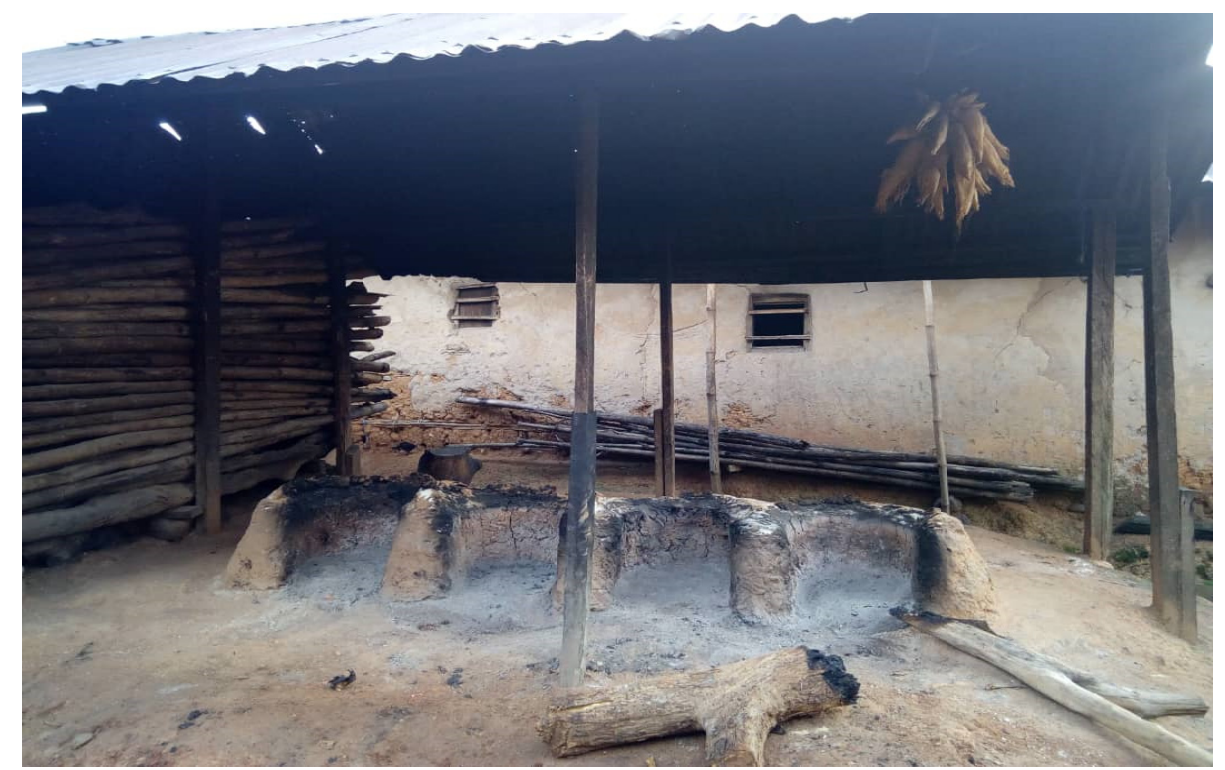

Figure 4. Attached kitchen constructed with wood, bamboos and zinc sheets 


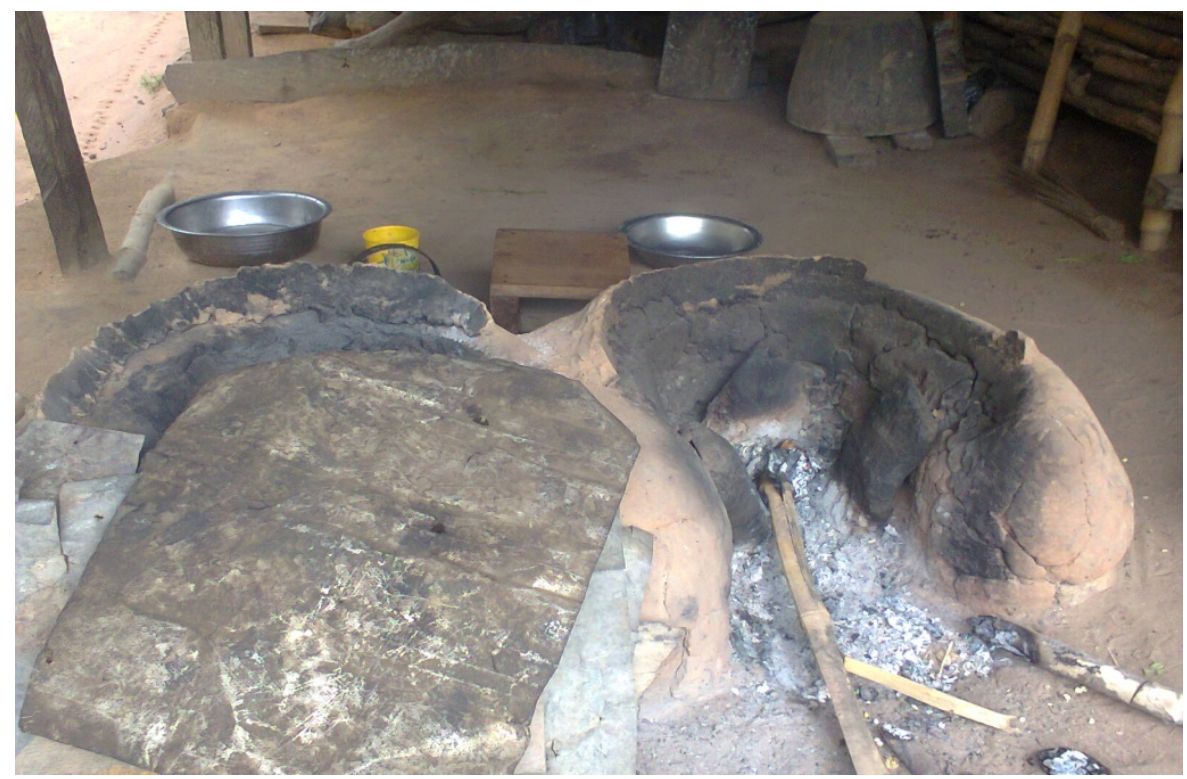

Figure 5. Kitchen design with circulation space and fire places clearly demarcated

Also, the study has shown that the conventional method of kitchen design requirement which is based on work triangle in contemporary designs does not matter in low-income traditional kitchen (Figure 5). The kitchen designs as observed are spacious, square or rectangular in shape with an overhang/provision for seasoning or drying of farm products as a preservation technique, with or without storage area (figure $6 \& 7$ ). What is most important to the respondents/users are the fire places which are of different sizes to accommodate all forms of cooking and frying pots, cassava processing (frying), space for placement of mortar for pounding yam, cocoyam and vegetables.

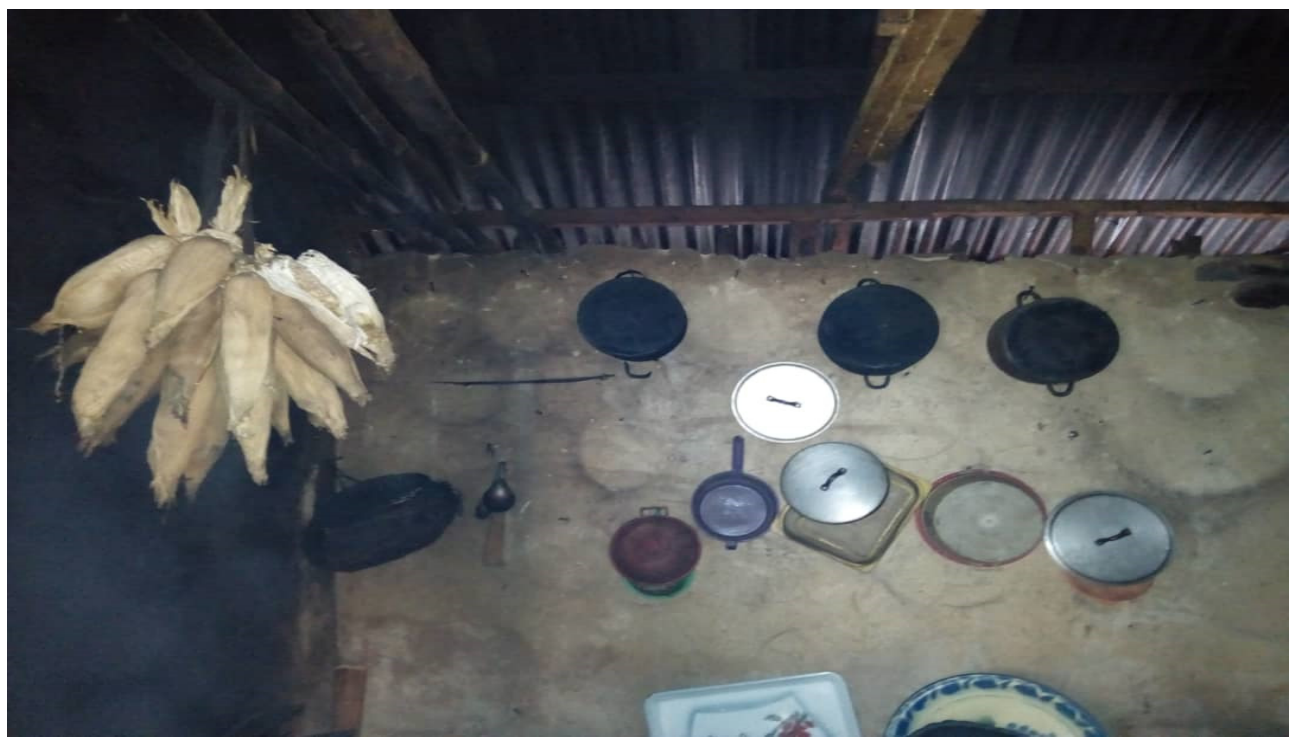

Figure 6. Traditional kitchen cabinet /storage pattern 


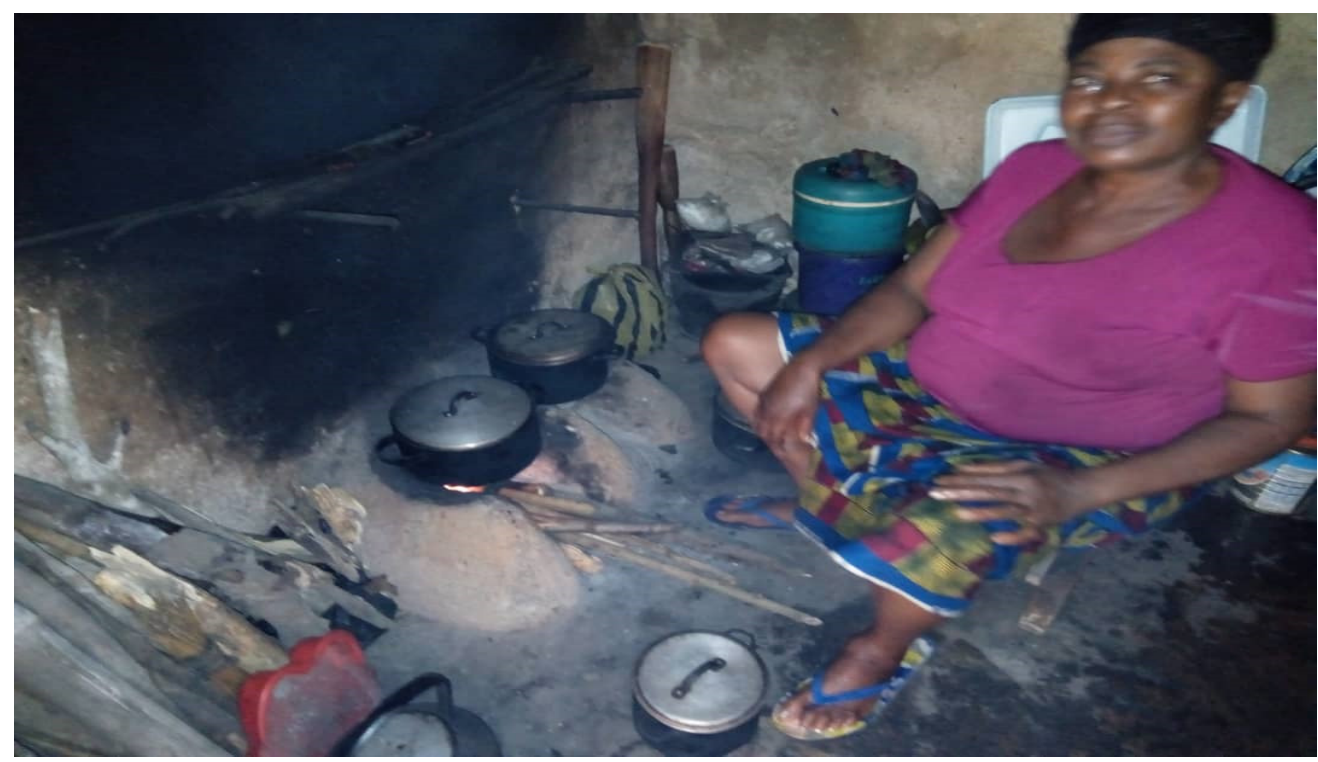

Figure 7. Traditional kitchen interior with fire places for different sizes of cooking pots

\section{Conclusion}

It is an established fact that modern day dwellings cannot be said to be efficiently designed without the inclusion of the kitchen space. Thus, the kitchen has become one of the most celebrated and important space in residential houses of today. However, this study has revealed that for the low-income populace both in cities and rural areas, the kitchen though very important space in the dwellings, attention is not given to it. The kitchen in these dwellings neither have any form of good design with work triangle, nor equipped with modern state-of-the-art furnishing which are a feature of modern kitchen. What is important is that there is always a provision for a kitchen. And for any elaborate kind of celebration which calls for preparation of food to serve much people as the culture of Africans are, the modern kitchen gives way to the traditional low-income kitchen where food preparation is done outside.

The study recommends that individual low-income housing developers should not be too rigid with their architectural traditional taste but are encouraged to have a blend of the traditional and that of the contemporary architecture in order to move with the dynamism of the architecture. Also, government, agencies and professionals must educate the low-income housing developers with the techniques of improving the traditional housing forms with contemporary elements with minimal cost. Thus, kitchens should form part of the designs of low-income housing in the interiors of dwellings for easy accessibility in times of unfavourable weather conditions in addition to their detached or attached kind of kitchen design arrangement for cultural reasons.

The study recommends that individual low-income housing developers should not be too rigid with their architectural traditional taste but are encouraged to have a blend of the traditional and that of the contemporary architecture in order to move with the dynamism of the architecture. Also, government, agencies and professionals must educate the low-income housing developers with the techniques of improving the traditional housing forms with contemporary elements with minimal cost.

\section{References}

Atamewan, E. E. (2017). Re-development of Minimum Housing Design Standards for Low-income Residential Dwellings in Bayelsa State, Nigeria. (Unpublished doctoral dissertation). Federal University of Technology, Minna, Nigeria.

Atamewan, E. E.,\& Olagunju, R.E. (2017). Sustainable Low-Income Housing and Practicable Minimum Design Standards in Bayelsa State, Nigeria. Journal of Sustainable Architecture and Civil Engineering, 20(3), 1424. https://doi.org/10.5755/j01.sace.20.3.18208

Bech-Danielsen, C. (2012). The Kitchen: An Architectural Mirror of Everyday Life and Societal Development. Journal of Civil Engineering and Architecture, 6(4), 457-469. https://doi.org/10.17265/19347359/2012.04.006

Borson, B. (2011). Life of an architect: The kitchen is key. 
Burnett, J. (1978). Social History of Housing: 1815-1970. Cambridge: The University Press.

Canada Mortgage and Housing Corporation. (2010). Accessible Housing by Design-Kitchens. Canada: CMHC 18-08-10.

Cromley, E. C. (2011). The Food Axis: Cooking, Eating, and the Architecture of American Houses. Virginia: University of Virginia Press.

Ettehad, S., Azeri, A. K.,\& Kari, G. (2014). The Role of Culture in Promoting Architectural Identity. European Online Journal of Natural and Social Sciences: Special Issue on Architecture, Urbanism, and Civil Engineering, 3(4), 1-10.

Gilly, L. (1997). Making the Most of Kitchens. London; Conran Octopus Ltd.

Gopinath, G.,\& Kulkarni, S. Y. (2014). The Impact of Socio-Cultural Factors on the Transformation of the Residential Architecture of Kerala.International Journal of Research, 1(5), 526-530.

Kinchin,J.,\& Aidan, O. (2011). Counter Space: Design and the Modern Kitchen. New York, MoMA.

Lupton, E., \& Miller, J. A. (1996). The Bathroom, the Kitchen, and the Aesthetics of Waste. Princeton; Architectural Press.

Overy, P. (2008). Light, Air and Openness: Modern Architecture between the Wars. London; Thames \& Hudson.

Parvizi, E. (2009). National architecture from the perspective of cultural identity, Journal of national studies, 3.

Shayan, H. (2011). Criteria for defining architectural identity. Journal of the village, 70.

Snodgrass, M. E. (2004).Encyclopaedia of Kitchen History. Fitzroy Dearborn Publishers. https://doi.org/10.4324/9780203319178

Sudjic, D. (1999). Home: The Twentieth-Century House. Glasgow, Festival Company Ltd.

\section{Copyrights}

Copyright for this article is retained by the author(s), with first publication rights granted to the journal.

This is an open-access article distributed under the terms and conditions of the Creative Commons Attribution license (http://creativecommons.org/licenses/by/4.0/). 